\title{
Spatio-temporal variability of amphipod assemblages associated with rhodolith seabeds
}

\author{
Sandra Navarro-Mayoral (iD) A, Victoria Fernandez-Gonzalez ${ }^{\text {, }}$ \\ Francisco Otero-Ferrer ${ }^{\mathrm{A}}$ and Fernando Tuya ${ }^{\mathrm{A}}$ \\ ${ }^{A}$ Grupo en Biodiversidad y Conservación, IU-ECOAQUA, Universidad de Las Palmas de Gran \\ Canaria, Marine Scientific and Technological Park, Courta. Taliarte s/n, E-35214 Telde, Spain. \\ ${ }^{B}$ Department of Marine Sciences and Applied Biology, University of Alicante, PO Box 99, \\ E-03080 Alicante, Spain. \\ ${ }^{\mathrm{C}}$ Corresponding author. Email: sandra.navarro102@alu.ulpgc.es
}

\begin{abstract}
Rhodolith seabeds are habitats underpinned by free-living calcareous macroalgae. We partitioned the relevance of the scale of temporal (four seasons throughout two successive years) and spatial (three depth strata: 18, 25 and $40 \mathrm{~m}$ ) variation on the diversity, structure and abundance of amphipod assemblages living in rhodolith seabeds from Gran Canaria Island. In total, 3996 individuals, belonging to 32 taxa, were identified. Multivariate analyses showed consistent differences in assemblage structure among seasons and depths; more diverse and abundant amphipod assemblages were often observed during spring at 18- and 25-m than at 40-m depth. Ovigerous females of Gammaropsis ostroumowi and Ampithoe ramondi were observed mainly at 18 and $25 \mathrm{~m}$. Juveniles of both species were exclusively recorded at 18 and $25 \mathrm{~m}$, so denoting a clear segregation in their population structure with depth. In summary, this study has demonstrated that the ecological pattern of amphipods associated with rhodolith seabeds can vary greatly across both time (seasons) and space (depth).
\end{abstract}

Additional keywords: algal biomass, Atlantic Ocean, Canary Islands, crustaceans, maerl, population structure.

Received 14 November 2019, accepted 6 April 2020, published online 26 May 2020

\section{Introduction}

Rhodoliths seabeds worldwide cover extensive subtidal environments, functioning as 'ecosystems engineers' (Teichert 2015). These communities are mainly composed by nongeniculate, free-living, calcareous macroalgae, belonging to the division Rhodophyta, which present a rugged appearance and diverse morphology (de O Figueiredo et al. 2007). In temperate waters of the Atlantic Ocean, the main species of rhodolith are those within the genus Lithothamnion and Phymatolithon (Konar et al. 2006). The ecological relevance of rhodolith seabeds is based on the fact that the branched and intertwined structure of these red algal nodules provides stable three-dimensional habitats for associated fauna (RiosmenaRodríguez et al. 2017). Rhodoliths are also colonised by epiflora, which provide a secondary habitat, increasing the spatial heterogeneity of rhodolith seabeds (Nelson et al. 2012; Riosmena-Rodríguez et al. 2017). Therefore, rhodoliths and attached epiflora facilitate associated epi- and infaunal assemblages, providing a large number of available ecological niches and protection against predators (Jones et al. 1994; De Grave 1999; Hinojosa-Arango and Riosmena-Rodríguez 2004; Amado-Filho et al. 2010; Thomsen 2010). For these reasons rhodolith seabeds are, indeed, considered 'hot spots' of biodiversity (Sciberras et al. 2009), supporting a higher diversity and abundance of species than do the surrounding sedimentary habitats (Neill et al. 2015). Despite their importance, the ecology of these habitats has received little attention, relative to communities supported by other seaweeds (Nelson et al. 2012).

Rhodolith seabeds are distributed worldwide within the photic zone, from 0 - to 200-m depth, mainly in environments under high light penetration and moderate levels of hydrodynamism (Foster 2001; Konar et al. 2006; Sciberras et al. 2009; RiosmenaRodríguez et al. 2017). Abrupt environmental gradients, which may occur through narrow vertical scales (i.e. from 0 - to $50-\mathrm{m}$ depth), can influence the distribution and abundance patterns of nearshore communities (Tuya et al. 2007; Brokovich et al. 2008). Variation in depth directly affects physical processes, such as levels of hydrodynamism, light attenuation, sedimentation, temperature and salinity (Fulton et al. 2005; Mindel et al. 2016), which alter the distribution and structure of rhodolith seabeds (Steller et al. 2007; Sciberras et al. 2009; Otero-Ferrer et al. 2020), including the size, morphology and physiology of individual rhodoliths and, consequently, the presence of associated epiflora and fauna (Steneck 1986; Grall and Hall-Spencer 2003; Peña and Bárbara 2008).

Amphipods are one of the most abundant epifaunal groups from rhodolith seabeds (De Grave 1999; Teichert 2015). These marine invertebrates include species with different trophic 
strategies (e.g. detritivores, omnivores, carnivores and herbivores), being prey for other crustaceans, polychaetes and many species of fish (Guerra-García et al. 2014; Jiménez Prada et al. 2015). Amphipods present sexual dimorphism (SainteMarie 1991), with females showing a brood pouch, or marsupium, where eggs are incubated until fully developed juveniles are released (Thiel 1998). The sex ratio of populations is often female-biased (Thiel 1998) and most species are iteroparous annuals, producing several generations during a year (SainteMarie 1991).

Initially, the distribution and abundance of amphipods living in rhodoliths is favoured by the large complexity of the habitat (Riosmena-Rodríguez et al. 2017). However, such patterns may notably differ among amphipod species and even among the phases of their life cycles (De Grave 1999; Sciberras et al. 2009; Teichert 2015). In particular, changes in the diversity, abundance and assemblage structure of amphipods across depths and varying temporal (seasonal) scales have been scarcely referenced in the literature, focusing on the ecology of amphipods living in rhodoliths.

Rhodolith beds in the Canary Islands (eastern Atlantic Ocean) occupy extensive areas across a wide bathymetric gradient, from $\sim 15-\mathrm{m}$ to $150-\mathrm{m}$ depth (Riera et al. 2013). Taking advantage of the spatial distribution of these habitats in the shallow subtidal $(15-40 \mathrm{~m})$, the present study aimed to partition the relevance of temporal (seasons and years) and spatial (three depth strata) scales on the diversity, structure and abundances of amphipod assemblages living in a rhodolith seabed located in the Gran Canaria Island. More specifically, rhodolith beds and associated epiflora and epifauna (here, amphipods) were seasonally studied at three depth strata (18, 25 and $40 \mathrm{~m}$ ) throughout two successive years (i.e. eight times). Initially, we expected that depth consistently affected the abundances of epiphytic flora and amphipods associated with rhodoliths, in particular over the two most abundant species, namely, Gammaropsis ostroumowi and Amphitoe ramondi, including the abundances of ovigerous females and juveniles. Second, we expected indirect positive effects of the presence of epiphytic flora on the richness and abundance of amphipods.

\section{Materials and methods}

Study region

The study was conducted at the eastern coast of Gran Canaria Island (Canary Islands, eastern Atlantic Ocean; see Supplementary materials Fig. S1, available at the journal's website) on a rhodolith bed near Gando Bay $\left(27^{\circ} 55^{\prime} 54^{\prime \prime} \mathrm{N}, 15^{\circ} 21^{\prime} 11^{\prime \prime} \mathrm{W}\right)$, during two successive years (December 2015 - October 2017). In this area, north-eastern trade winds notably determine the local oceanographic patterns. Wind waves, with higher prevalence during summer, generate near-bottom turbulence at lower depths, affecting shallow subtidal habitats. Rhodolith beds appear locally distributed as mosaics of neighbouring habitat patches, between 15- and 50-m depth (Fig. S1). The study took place at three different depths $(18,25$ and $40 \mathrm{~m})$ that encompass the local bathymetric range in the vertical distribution of rhodolith beds, while keeping SCUBA security standards during field collections at all times. These rhodolith beds are mainly composed of several genera of red calcareous algae, such as Lithothamnion spp. and
Phymatolithon spp. (Haroun et al. 2002; Pardo et al. 2014; Otero-Ferrer et al. 2020).

\section{Sampling design and collection of samples}

Sampling was conducted through two successive years (December 2015 - October 2017), including four seasonal sampling campaigns in autumn (December), winter (March), spring (July) and summer (October; see fig. A2 in Otero-Ferrer et al. 2020 for in situ measures of water temperatures and PAR light). Samples were taken using SCUBA, while keeping security standards during field collections. At each depth stratum, five random replicates $(25 \times 25 \mathrm{~cm})$ were taken each time, by collecting all rhodolith nodules up to $5 \mathrm{~cm}$ inside the sea bottom. SCUBA divers collected samples by hand, and they were rapidly enclosed within cloth bags. Samples were preserved in a freezer at $-20^{\circ} \mathrm{C}$ until sorting.

\section{Sample processing}

Each sample was defrosted and filtered through a 0.5-mm sieve to remove sand and debris from the rhodoliths. From all organisms retained by the mesh, amphipods were sorted and then identified under a stereomicroscope (Leica, EZ4W, Wetzlar, Germany) to the lowest possible taxonomic level, in most cases, to the species level. The taxonomic guide provided by Hayward and Ryland (1990), and specific references from the Macaronesian area (Riera et al. 2013; Png-Gonzalez et al. 2014; García-Sanz et al. 2016), were used for species identification. For the two most abundant species, namely, G. ostroumowi and $A$. ramondi, the relative abundances were also partitioned according to ovigerous females and juveniles. To distinguish juveniles, we used the size criterion and the absence of secondary sexual characters, such as the size and shape of the gnathopods and the presence of oostegites or penial papillae (Fernandez-Gonzalez 2017). Species richness and abundances per sample were standardised according to the amount of available habitat (i.e. the biomass of rhodoliths). Epiphytic macroalgae were removed from each sample, identified under a microscope (Leica, DM1000) and, subsequently, dried at $70^{\circ} \mathrm{C}$ for $48 \mathrm{~h}$, so as to obtain their dry weight.

\section{Statistical analyses}

All modelling and testing were here implemented in the $\mathrm{R}_{3.6 .1}$ statistical environment (https:/cran.r-project.org/bin/windows/ base/old/3.6.1/). Generalised linear models (GLMs), using a negative binomial family because of over-dispersion of abundance data, were fitted to the multivariate abundance-data matrix, by means of the 'mvabund' package (Wang et al. 2012). We tested the multivariate hypothesis of whether the amphipod assemblage structure varied among depths (fixed factor with three levels: 18, 25 and $40 \mathrm{~m}$ ), seasons (fixed factor with four levels: winter, spring, summer and autumn) and years (random factor with two levels). The importance of these multivariate differences was tested by the 'Anova' function, which provided an analysis of deviance. $P$-values were then calculated using 999 resampling iterations via a PIT-trap resampling procedure. The relative contribution (in terms of \%) of each of the three factors to explain the overall multivariate variance was estimated via the 'best.r.sq' function. 


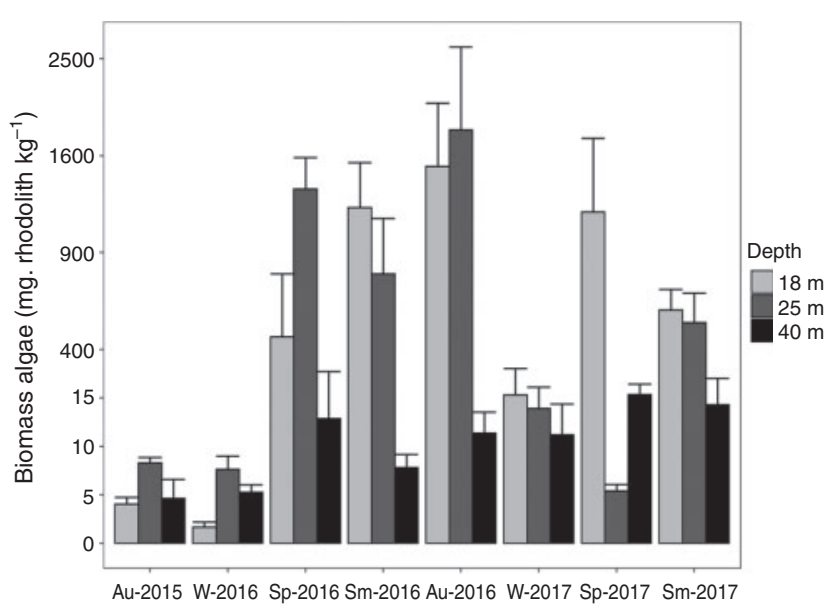

Fig. 1. Temporal variation in the epiphytic algal biomass $(+$ s.e. of the mean) at 18-, 25- and 40-m depth. Au, autumn; W, winter; Sp, spring; and $\mathrm{Sm}$, summer.

Mixed-effects GLMs were fitted to univariate responses, including the following: the richness and total abundance of amphipods, as well as the abundances of the most abundant species (Gammaropsis ostroumowi, Ampithoe ramondi, Pardia punctata, Dexamine spinosa, Pseudoprotella phasma and Ampithoe helleri), and the abundances of ovigerous females and juveniles of $G$. ostroumowi and $A$. ramondi, i.e. the two most abundant species. Mixed-effects GLMs were fitted by means of the 'Ime4' (https://cran.r-project.org/web/packages/ lme4/index.html) and 'lmerTest' packages (Kuznetsova et al. 2017) to test for differences among depths (three levels: 18, 25 and $40 \mathrm{~m}$ ) and seasons (four levels: winter, spring, summer and autumn), as fixed factors, and years (two levels) as a random factor. Models were fitted using a Poisson, or a negative binomial, family distribution of residuals, with a square-root link function. For all fitted GLMs, diagnosis plots of residuals and Q-Q plots were visually inspected to check the appropriateness of the fitted models (Harrison et al. 2018). To select models with the largest parsimony, the Akaike information criterion (AIC) was obtained for the null model and models containing only the covariate (the biomass of rhodoliths per sample) and the entire set of predictors (full model including the three factors). Because the AIC was larger when the random effect ('year') was considered for univariate responses, this factor was finally not included. Finally, simple linear regressions tested whether the richness and total abundance of amphipods was predicted by the total epiphytic algal biomass, separately for each depth stratum.

\section{Results}

In total, 3996 amphipods were counted, including 32 taxa (25 determined at the species level, four at the genus level and three at the family level; Fig. S2). The multivariate structure of amphipod assemblages differed among depths, seasons and years (see Supplementary materials Tables S1, S2). The factors 'year' and 'depth' explained a larger amount of variation in the multivariate structure $(\sim 10$ and $12 \%$ respectively) than did 'season' ( $6 \%)$.

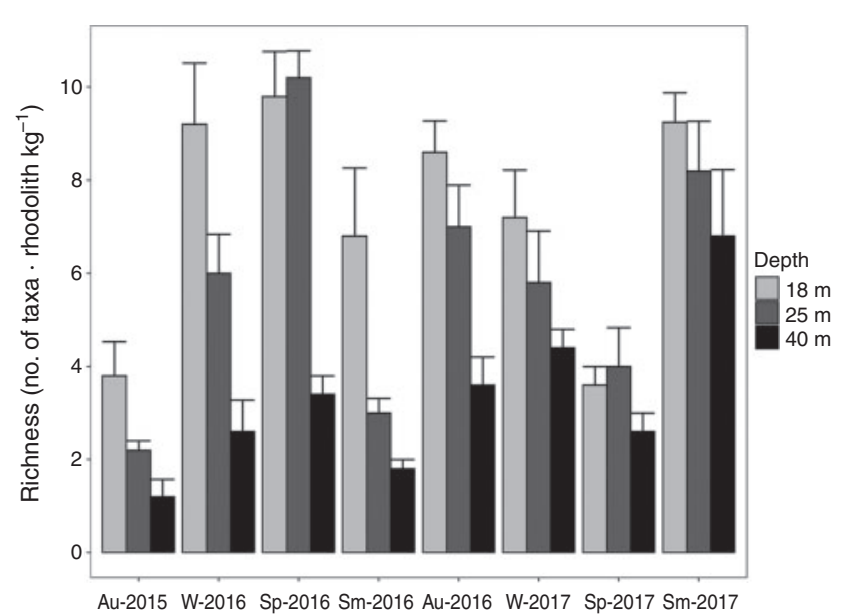

Fig. 2. Temporal variation in the richness (+s.e. of the mean) of amphipods (number of taxa, standardised per the amount of available habitat) at 18-, 25- and 40-m depth. Au, autumn; W, winter; Sp, spring; and Sm, summer.

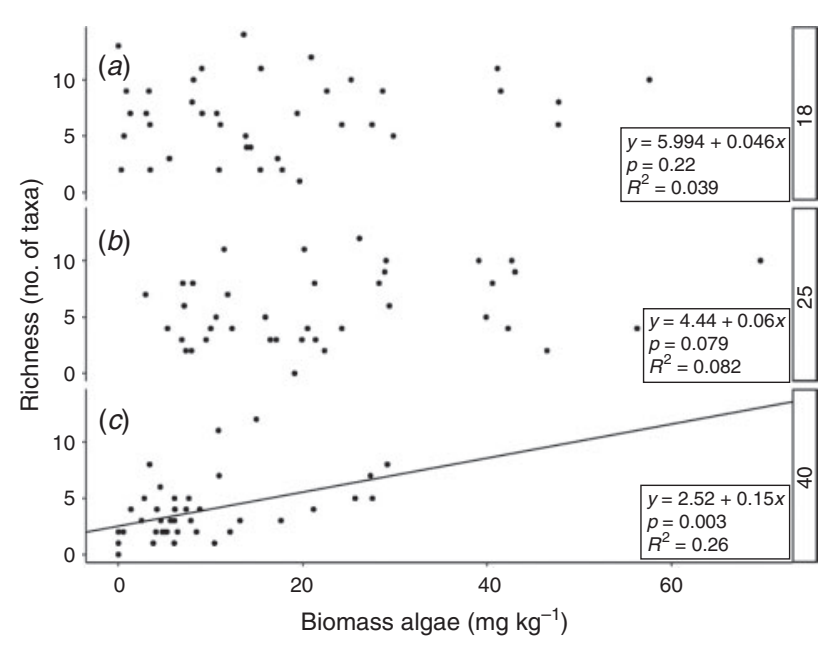

Fig. 3. Relationship between the richness of amphipods (standardised per kilogram of rhodolith) and the epiphytic algal biomass (square-root transformed) at (a) 18-, (b) 25- and (c) 40-m depth. The relationship was significant only at $40 \mathrm{~m}$.

In general, higher biomasses of epiphytic algae attached to rhodoliths were collected at 18 and $25 \mathrm{~m}$ than at $40 \mathrm{~m}$ (Fig. 1; 'depth $(40 \mathrm{~m})$ '; Table S3, $P<0.001)$. A larger biomass of epiphytic algal biomass was observed in spring and summer (Fig. 1) than in winter (Fig. 1; 'season (winter)'; Table S4, $P<0.005$ ), particularly at $18 \mathrm{~m}$ in winter of 2016. The richness of amphipods at 18 and $25 \mathrm{~m}$ was significantly larger than that at 40-m depth (Fig. 2; 'depth (40 m)'; Table S5, $P<0.001)$. In particular, in spring 2016, the largest number of taxa was recorded at 18- and 25-m depths (Fig. 2). There was a significant positive relationship between the richness of taxa and the epiphytic algal biomass at $40 \mathrm{~m}\left(P<0.001, R^{2}=0.2601\right)$, but not at 18 and $25 \mathrm{~m}$ (Fig. 3).

The total abundance of amphipods decreased significantly with depth; larger abundances were observed at 18 and $25 \mathrm{~m}$ 


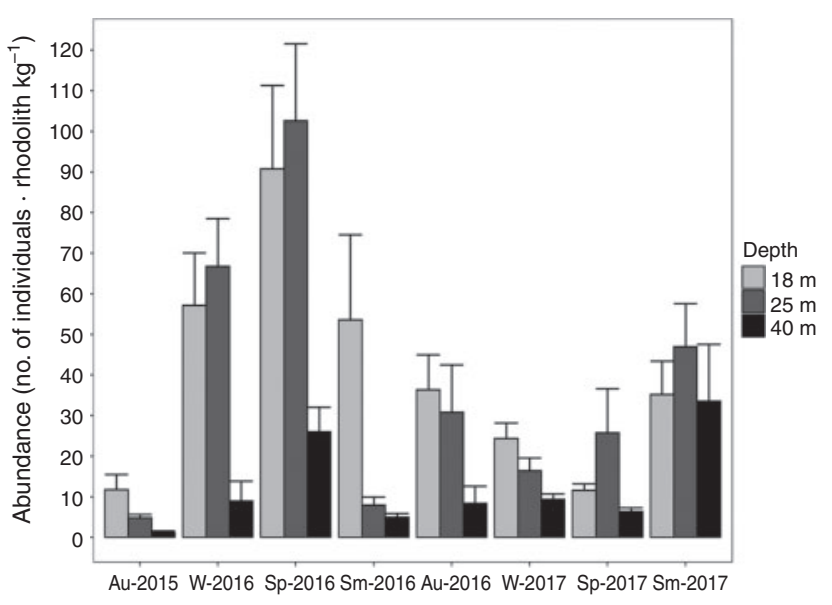

Fig. 4. Temporal variation in the total abundance ( + s.e. of the mean) of amphipods (number of individuals standardised per the amount of available habitat) at 18, 25 and $40 \mathrm{~m}$. Au, autumn; W, winter; Sp, spring; and Sm, summer.

than at $40 \mathrm{~m}$ (Fig. 4; 'depth (40 m)'; Table S6, $P<0.001)$. A significant positive relationship was detected between the total abundance of amphipods and the epiphytic algal biomass at $40 \mathrm{~m}\left(P<0.001, R^{2}=0.1265\right)$, but not at 18 and $25 \mathrm{~m}$ (Fig. 5). Six species accounted for $75.5 \%$ of the total abundance of amphipods, including G. ostroumowi, A. ramondi, D. spinosa, P. punctata, P. phasma and A. helleri (Fig. 6; Fig. S2). In general, these species followed a similar bathymetrical pattern as that reported for the total abundance of amphipods, with larger abundances at 18 and $25 \mathrm{~m}$ than at $40 \mathrm{~m}$ (Fig. 6; Tables S2, S7-S12). The species G. ostroumowi (Fig. 6a) and A. ramondi (Fig. 6b) dominated the assemblage, with a total of 1520 and 890 individuals respectively ( $60.3 \%$ of the total abundance). Both species showed larger abundances at 18 and $25 \mathrm{~m}$ than at $40 \mathrm{~m}$ (Fig. 6a,b).

Juveniles of G. ostroumowi were recorded only at 18 and $25 \mathrm{~m}$, but were absent at $40 \mathrm{~m}$ (Fig. 7); larger abundances were recorded in winter and spring (Fig. 7; 'season (winter) and (spring)'; Table S12, $P<0.001$ ). Ovigerous females were observed throughout the entire study, including an abundance peak at $18 \mathrm{~m}\left(6.6 \pm 1.9\right.$ ind. $\mathrm{kg}^{-1}$; at winter (2016; Fig. 8; 'season (winter)'; Table S13, $P<0.001$ ). A similar temporal pattern was observed for $A$. ramondi, with juveniles being recorded only at 18 and $25 \mathrm{~m}$, and the largest abundances in spring 2016 (Fig. 8; 'season (spring)'; Table S14, $P<0.05$ ). Ovigerous females of $A$. ramondi reached the largest abundances in spring 2016 at 25-m depth, despite no statistically significant differences being observed (Fig. 8, Table S15).

\section{Discussion}

Our results showed differences in the diversity, structure and abundance of amphipod assemblages with depth, which were consistent over time. In general, a higher richness and abundance of amphipods were observed at 18 and $25 \mathrm{~m}$ than at $40 \mathrm{~m}$.

Most species of amphipod from the present study have also been found in other infra-littoral and circa-littoral habitats (Pérès 1967; De Grave 1999). In our case, the overall richness

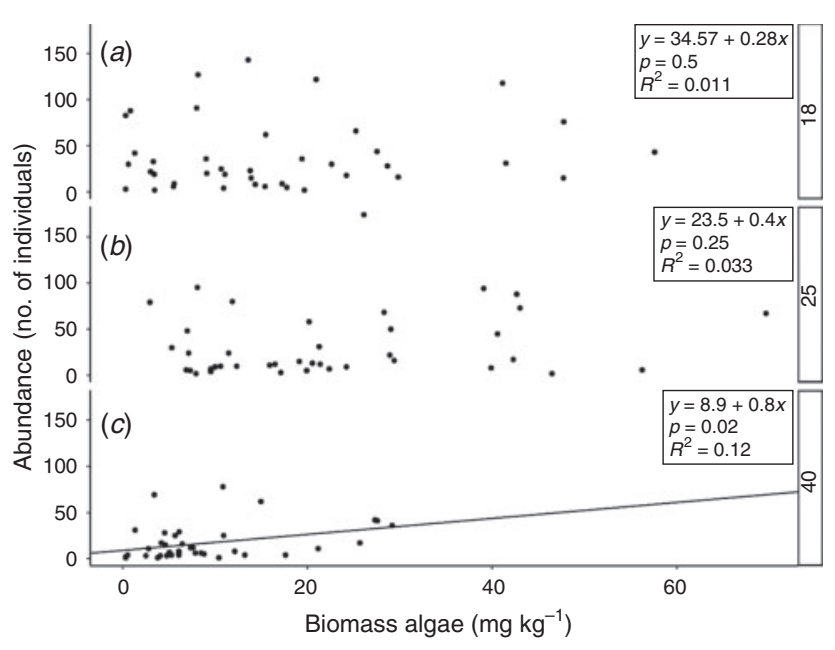

Fig. 5. Relationship between the total abundance of amphipods (standardised per kilogram of rhodolith) and the epiphytic algal biomass (square-root transformed) at (a) 18-, (b) 25- and (c) 40-m depth. The relationship was significant only at $40 \mathrm{~m}$.

(32 taxa) was greater than in beds dominated by the green alga Caulerpa prolifera (27 taxa) and meadows of the seagrass Cymodocea nodosa (17 taxa; Png-Gonzalez et al. 2014). This seagrass facilitates amphipod assemblages because, similar to rhodoliths, the structural complexity increased the amount of available colonisation space and a range of trophic resources (Taylor and Cole 1994; Sánchez-Moyano et al. 2007). From the total of 32 amphipods recorded here, 16 species coincided with those observed by Png-Gonzalez et al. (2014), which suggests their adaptation to life under varying conditions provided by different nearshore habitats.

Initially, changes in amphipod assemblages may be linked to variation in habitat structure with depth, such as the size of the rhodolith nodules and the biomass of epiphytic macroalgae. Recently, Otero-Ferrer et al. (2020) described, for the study area, an increase in rhodolith size (diameter) from 18 to $25 \mathrm{~m}$, and a decrease from 25 to $40 \mathrm{~m}$, which can promote larger abundances of amphipods at $25 \mathrm{~m}$. At the same time, the lower richness and abundance of amphipods at $40 \mathrm{~m}$ is coincident with a significant decrease in epiphytic algal biomass. The bathymetrical pattern shown by epiphytic algal biomass was probably linked with a higher light availability at shallower depths (Connell 2005), which has also been described from other rhodolith seabeds (Pascelli et al. 2013; McConnico et al. 2017). The presence of vegetation (here, epiphytic algae on rhodoliths) can enhance the heterogeneity and complexity of the habitat available for epifauna (i.e. amphipods), increasing their abundance and species richness relative to unvegetated habitats (de O Figueiredo et al. 2007; Vázquez-Luis et al. 2009). This process, where a primary substrate (here, rhodoliths) supports a secondary habitat created by sessile organisms (here, epiphytic algae), which concurrently facilitates the diversity and abundance of invertebrates, is an example of 'habitat cascade' (Thomsen et al. 2010). The presence of epiphytic algae associated with rhodoliths can alter local hydrodynamic regimes (Eckman 1983), the availability of colonisable space, the 


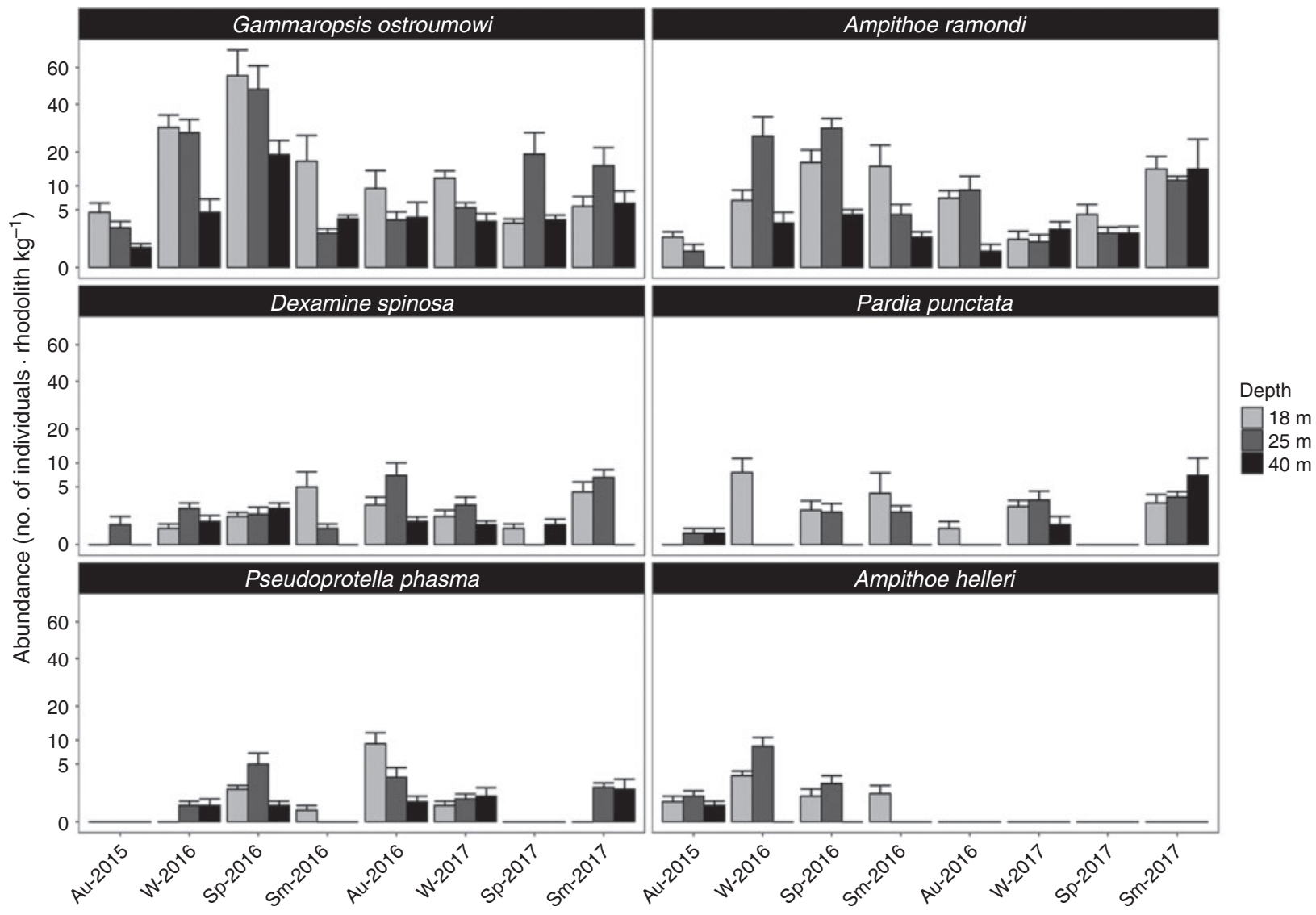

Fig. 6. Abundances ( + s.e. of the mean) of the six dominant amphipod species (mean number of individuals standardised per the amount of available habitat) at 18, 25 and $40 \mathrm{~m}$. Au, autumn; W, winter; Sp, spring; and Sm, summer.

(a)

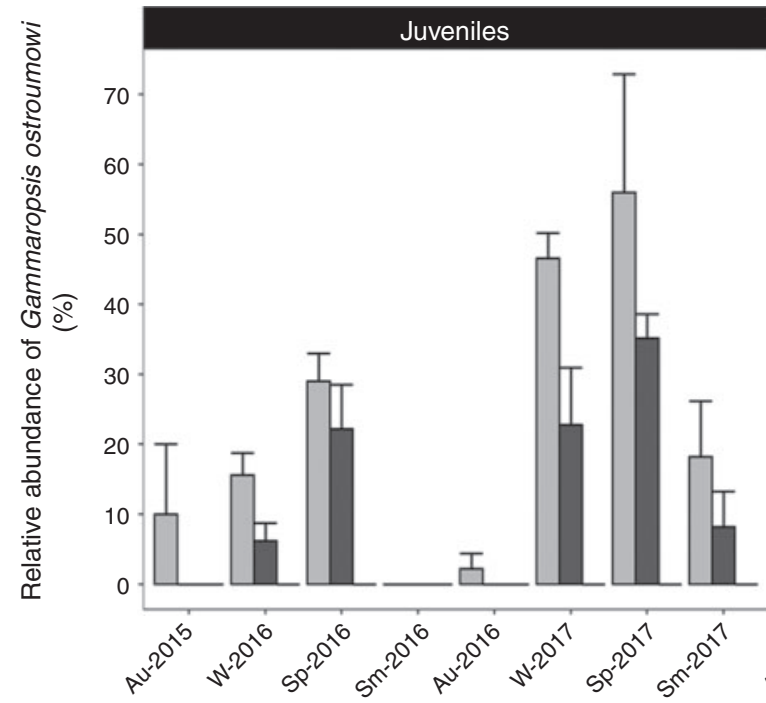

(b)

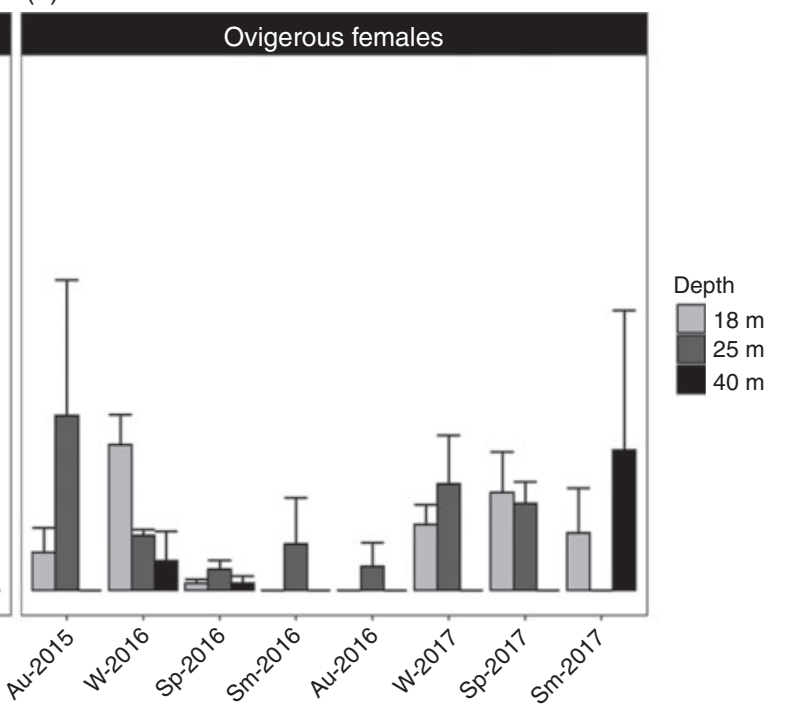

Fig. 7. Temporal variation in the relative abundances (+s.e. of the mean) of (a) juveniles and (b) ovigerous females of Gammaropsis ostroumowi (proportion of individuals standardised per the amount of available habitat) at 18-, 25- and 40-m depth. 
(a)

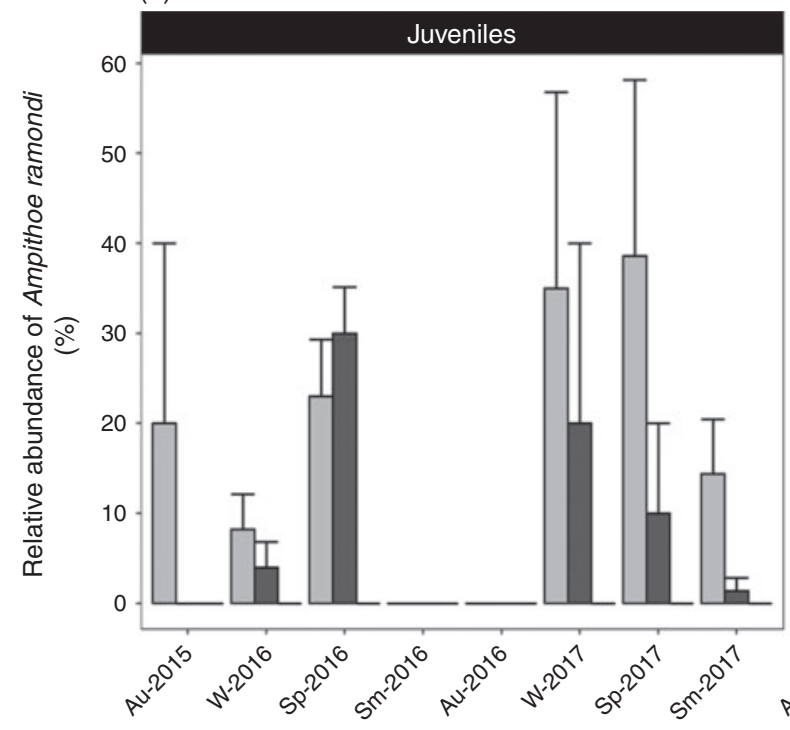

(b)

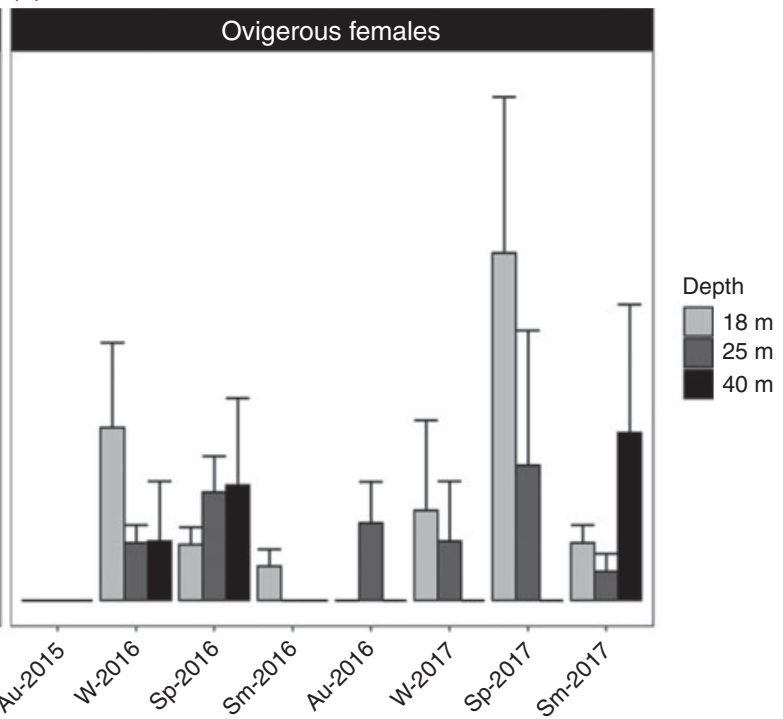

Fig. 8. Temporal variation in the relative abundance ( + s.e. of the mean) of (a) juveniles and (b) ovigerous females of Ampithoe ramondi (proportion of individuals standardised per the amount of available habitat) at 18-, 25- and 40-m depth.

quantity of food (Cunha et al. 2000), the intensity of predation and competition, as well as larval dispersal and further recruitment (Steller and Foster 1995).

Amphipods have a wide trophic diversity, including herbivores, carnivores and omnivores (Guerra-García et al. 2014). However, most species feed on detritus (Sciberras et al. 2009; Guerra-García et al. 2014), which plays an important role as a trophic resource for marine invertebrates, being one of the main trophic pathways in the marine realm (Zimmerman et al. 1979), particularly in and around vegetated habitats (Vázquez-Luis et al. 2009; Michel et al. 2015). In our study, the most abundant species, G. ostroumowi, has been described from hard substrates and habitats dominated by algae and seagrasses (ZakhamaSraieb et al. 2011). The diet of G. ostroumowi mainly consists of detritus (99\%, according to Guerra-García et al. 2014), being able to take advantage of the heterogeneity of the rhodolith seabeds to find large amounts of food (Sciberras et al. 2009). Individuals belonging to the family Ampithoidae (here, $A$. ramondi and $A$. helleri) and the species $D$. spinosa are mainly herbivores (Ruffo 1982; Vázquez-Luis et al. 2009; GuerraGarcía et al. 2014). These species may feed on epiphytic algae growing on rhodoliths, because they showed a larger presence at 18 and $25 \mathrm{~m}$ than at $40 \mathrm{~m}$, which coincides with the largest epiphytic algal biomasses throughout the study.

Temporal variation in the richness and abundance of amphipods can be attributed to changes in habitat structure through varying time scales, particularly seasonal changes, which alter habitat complexity through increased occurrence of epiphytes and associated algae (Sanchez-Jerez 1997). In general, our study showed that abundances of amphipods were higher during spring (July) and summer (October) than in autumn (December) and winter (March). This agrees, for example, with de O Figueiredo et al. (2007), who observed larger abundances of amphipods in summer and autumn but showed a reduction in the abundances in winter. As reported by Pascelli et al. (2013), reduced irradiance, low temperatures and strong waves cause periodical disturbances on these habitats in winter. For example, wave-induced resuspension of sediments and the movement and subsequent erosion of rhodoliths promotes the removal of epiphytes from rhodoliths, affecting associated epifauna (Steller and Foster 1995; Amado-Filho et al. 2007, 2010). In our study, changes in epiphytic algal biomass on rhodoliths may have some influence over the seasonal dynamics of amphipod assemblages. However, there should be other relevant factors involved in such temporality, because the amount of variation explained by the biomass of epiphytic algae was small.

Amphipods show a diversity of life-history patterns, which may be influenced, among other factors, by latitude, depth and salinity (Appadoo and Myers 2004), as well as local habitat conditions, such as seasonality in the availability of food resources or shelter (Sainte-Marie 1991). In this way, iteroparity is a common reproduction strategy in invertebrates. Most amphipods are, in turn, iteroparous annuals, producing several generations during a year (Sainte-Marie 1991). The population structure of the two most abundant species, namely, G. ostroumowi and A. ramondi, showed a greater relative abundance of juveniles than of ovigerous females through the 2 years of sampling. These results are consistent with studies from rhodolith seabeds in the Gulf of California, in which juvenile individuals were consistently more abundant than adults at certain times (RiosmenaRodríguez and Medina-López 2010), mainly during reproductive periods (Johnson et al. 2001). In rhodolith seabeds, the amount of energy available for the reproduction of amphipods depends on environmental conditions, including light and food availability and, therefore, the presence of epiphytic algae (Jeong et al. 2009; Riosmena-Rodríguez et al. 2017).

In our study, the two most abundant species, namely, G. ostromowi and A. ramondi, presented juveniles only at 18and 25-m depth. This result agrees with that of the study conducted by Sainte-Marie (1991), who postulated that the 
reproductive potential of the family Lysianassidae can be reduced at high depths. In this way, juvenile amphipods may find, at 18 and $25 \mathrm{~m}$, shelter from predators and favourable food conditions, which can lead to a greater and optimal growth of populations of both G. ostroumowi and A. ramondi (Jeong et al. 2009). However, more exhaustive studies of the population structure of amphipods through bathymetric gradients are necessary to confirm this hypothesis.

\section{Conclusions}

This is the first study attempting to explore, at the same time, changes in the diversity, structure and abundance of amphipods associated with rhodolith seabeds through several depth strata and times. Overall, a larger diversity and abundance of amphipods were observed at 18 and $25 \mathrm{~m}$ than at $40 \mathrm{~m}$. The population structure of the two most abundant amphipods showed a clear bathymetric segregation, with the presence of juveniles exclusively at 18 - and $25-\mathrm{m}$ depth. The significant variation through spatial (here, depth) and temporal (here, seasons) scales, which determine the diversity, structure and abundance of amphipods, points to the presence of a secondary habitat provided by epiphytic algae on rhodoliths, as a mechanism partially influencing such ecological patterns.

\section{Conflicts of Interest}

The authors declare that they have no conflicts of interest.

\section{Declaration of funding}

This work was partially financed by the Excellence International Campus of the Canary Islands (CEI-Canarias), the Agency for Research, Innovation and Information Society of the Canary Islands and the EcoAqua European project (ERA CHAIR program - Grant Agreement no. 621341).

\section{Acknowledgements}

We acknowledge T. Sánchez and M. Cosme de Esteban for their extraordinary logistical support during sampling and 'Puertos del Estado' (Spain) for the supply of some oceanographic data.

\section{References}

Amado-Filho, G. M., Maneveldt, G., Manso, R. C. C., Marins-Rosa, B. V., Pacheco, M. R., and Guimarães, S. M. P. B. (2007). Structure of rhodolith beds from 4 to 55 meters deep along the southern coast of Espírito Santo State, Brazil. Ciencias Marinas 33(4), 399-410. doi:10. 7773/CM.V33I4.1148

Amado-Filho, G. M., Maneveldt, G., Pereira-Filho, G. H., Manso, R. C. C., and Bahia, R. (2010). Seaweed diversity associated with a Brazilian tropical rhodolith bed. Ciencias Marinas 36(4), 371-391.

Appadoo, C., and Myers, A. A. (2004). Reproductive bionomics and life history traits of three gammaridean amphipods, Cymadusa filosa Savigny, Ampithoe laxipodusAppadoo and Myers and Mallacoota schellenbergi Ledoyer from the tropical Indian Ocean (Mauritius). Acta Oecologica 26(3), 227-238. doi:10.1016/J.ACTAO.2004.06.002

Brokovich, E., Einbinder, S., Shashar, N., Kiflawi, M., and Kark, S. (2008). Descending to the twilight-zone: changes in coral reef fish assemblages along a depth gradient down to $65 \mathrm{~m}$. Marine Ecology Progress Series 371, 253-262. doi:10.3354/MEPS07591

Connell, S. D. (2005). Assembly and maintenance of subtidal habitat heterogeneity: synergistic effects of light penetration and sedimentation. Marine Ecology Progress Series 289, 53-61. doi:10.3354/MEPS289053
Cunha, M. R., Sorbe, J. C., and Moreira, M. H. (2000). The amphipod Corophium multisetosum (Corophiidae) in Ria de Aveiro (NW Portugal). I. Life history and aspects of reproductive biology. Marine Biology 137(4), 637-650. doi:10.1007/S002270000384

De Grave, S. (1999). The influence of sedimentary heterogeneity on within maerl bed differences in infaunal crustacean assemblage. Estuarine, Coastal and Shelf Science 49(1), 153-163. doi:10.1006/ECSS.1999. 0484

de O Figueiredo, M. D., Santos-de Menezes, K., Costa-Paiva, E. M., Paiva, P. C., and Ventura, C. R. R. (2007). Experimental evaluation of rhodoliths as living substrata for infauna at the Abrolhos Bank, Brazil. Ciencias Marinas 33(4), 427-440. doi:10.7773/CM.V33I4.1221

Eckman, J. E. (1983). Hydrodynamic processes affecting benthic recruitment 1. Limnology and Oceanography 28(2), 241-257. doi:10.4319/LO. 1983.28.2.0241

Fernandez-Gonzalez, V. (2017). Fouling amphipods on marine aquaculture facilities: ecological interactions and potential applications. Doctoral Dissertation, Universitat d'Alacant - Universidad de Alicante, Spain.

Foster, M. S. (2001). Rhodoliths: between rocks and soft places. Journal of Phycology 37(5), 659-667. doi:10.1046/J.1529-8817.2001.00195.X

Fulton, C. J., Bellwood, D. R., and Wainwright, P. C. (2005). Wave energy and swimming performance shape coral reef fish assemblages. Proceedings. Biological Sciences 272(1565), 827-832. doi:10.1098/ RSPB.2004.3029

García-Sanz, S., Navarro, P. G., Png-Gonzalez, L., and Tuya, F. (2016). Contrasting patterns of amphipod dispersion in a seagrass meadow between day and night: consistency through a lunar cycle. Marine Biology Research 12(1), 56-65. doi:10.1080/17451000.2015.1069357

Grall, J., and Hall-Spencer, J. M. (2003). Problems facing maerl conservation in Brittany. Aquatic Conservation 13, S55-S64. doi:10.1002/AQC.568

Guerra-García, J. M., Tierno de Figueroa, J. M., Navarro-Barranco, C., Ros, M., Sánchez-Moyano, J. E., and Moreira, J. (2014). Dietary analysis of the marine Amphipoda (Crustacea: Peracarida) from the Iberian Peninsula. Journal of Sea Research 85, 508-517. doi:10.1016/J.SEARES.2013.08.006

Haroun, R. J., Gil-Rodríguez, M. C., de Castro, J. D., and Prud'Homme van Reine, W. F. (2002). A checklist of the marine plants from the Canary Islands (central eastern Atlantic Ocean). Botanica Marina 45(2), 139169. doi:10.1515/BOT.2002.015

Harrison, X. A., Donaldson, L., Correa-Cano, M. E., Evans, J., Fisher, D. N., Goodwin, C. E. D., Robinson, B. S., Hodgson, D. J., and Inger, R. (2018). A brief introduction to mixed effects modelling and multi-model inference in ecology. PeerJ 6, e4794. doi:10.7717/PEERJ.4794

Hayward, P. J., and Ryland, J. S. (Eds) (1990). 'The Marine Fauna of the British Isles and North-West Europe. Vol. 1: Introduction and Protozoans to Arthropods.' (Clarendon Press: Oxford, UK.)

Hinojosa-Arango, G., and Riosmena-Rodríguez, R. (2004). Influence of rhodolith-forming species and growth form on associated fauna of rhodolith beds in the central-west Gulf of California, México. Marine Ecology 25(2), 109-127. doi:10.1111/J.1439-0485.2004.00019.X

Jeong, S. J., Yu, O. H., and Suh, H. L. (2009). Reproductive patterns and secondary production of Gammaropsis japonicus (Crustacea, Amphipoda) on the seagrass Zoster amarina of Korea. Hydrobiologia 623(1), 63-76. doi:10.1007/S10750-008-9648-X

Jiménez Prada, P., Hachero Cruzado, I., and Guerra García, J. M. (2015). Importancia de los anfípodos en la dieta de especies de interés acuícola del litoral andaluz. Zoologica Baetica 26, 3-29.

Johnson, W. S., Stevens, M., and Watling, L. (2001). Reproduction and development of marine peracaridans. Advances in Marine Biology 39, $107-261$.

Jones, C. G., Lawton, J. H., and Shachak, M. (1994). Organisms as ecosystem engineers. Oikos 69, 130-147.

Konar, B., Riosmena-Rodriguez, R., and Iken, K. (2006). Rhodolith bed: a newly discovered habitat in the North Pacific Ocean. Botanica Marina 49(4), 355-359. doi:10.1515/BOT.2006.044 
Kuznetsova, A., Brockhoff, P. B., and Christensen, R. H. B. (2017). lmerTest package: tests in linear mixed effects models. Journal of Statistical Software 82(13). doi:10.18637/JSS.V082.I13

McConnico, L. A., Carmona, G. H., Morales, J. S. M., and Rodríguez, R. R. (2017). Temporal variation in seaweed and invertebrate assemblages in shallow rhodolith beds of Baja California Sur, México. Aquatic Botany 139, 37-47. doi:10.1016/J.AQUABOT.2017.02.007

Michel, L. N., Dauby, P., Gobert, S., Graeve, M., Nyssen, F., Thelen, N., and Lepoint, G. (2015). Dominant amphipods of Posidonia oceanica seagrass meadows display considerable trophic diversity. Marine Ecology 36(4), 969-981. doi:10.1111/MAEC.12194

Mindel, B. L., Neat, F. C., Trueman, C. N., Webb, T. J., and Blanchard, J. L. (2016). Functional, size and taxonomic diversity of fish along a depth gradient in the deep sea. PeerJ 4, e2387. doi:10.7717/PEERJ.2387

Neill, K. F., Nelson, W. A., D’Archino, R., Leduc, D., and Farr, T. J. (2015). Northern New Zealand rhodoliths: assessing faunal and floral diversity in physically contrasting beds. Marine Biodiversity 45(1), 63-75. doi:10. 1007/S12526-014-0229-0

Nelson, W. A., Neill, K., Farr, T., Barr, N., D'archino, R., Miller, S., \& Stewart, R. (2012). Rhodolith beds in northern New Zealand: characterisation of associated biodiversity and vulnerability to environmental stressors. New Zealand Aquatic Environment and Biodiversity report, 99, 106. Wellington, New Zealand.

Otero-Ferrer, F., Cosme, M., Tuya, F., Espino, F., and Haroun, R. (2020). Effect of depth and seasonality on the functioning of rhodolith seabeds. Estuarine, Coastal and Shelf Science 235, 106579. doi:10.1016/J.ECSS.2019.106579

Pardo, C., Lopez, L., Peña, V., Hernández-Kantún, J., Le Gall, L., Bárbara, I., and Barreiro, R. (2014). A multilocus species delimitation reveals a striking number of species of coralline algae forming maerl in the OSPAR maritime area. PLoS One 9(8), e104073. doi:10.1371/ JOURNAL.PONE.0104073

Pascelli, C., Riul, P., Riosmena-Rodríguez, R., Scherner, F., Nunes, M., Hall-Spencer, J. M., Cabral de Oliveira, E., and Horta, P. (2013). Seasonal and depth-driven changes in rhodolith bed structure and associated macroalgae off Arvoredo island (southeastern Brazil). Aquatic Botany 111, 62-65. doi:10.1016/J.AQUABOT.2013.05.009

Peña, V., and Bárbara, I. (2008). Maërl community in the north-western Iberian Peninsula: a review of floristic studies and long-term changes. Aquatic Conservation 18(4), 339-366. doi:10.1002/AQC.847

Pérès, J. M. (1967). The Mediterranean benthos. Oceanography and Marine Biology - An Annual Review 5, 449-533.

Png-Gonzalez, L., Vázquez-Luis, M., and Tuya, F. (2014). Comparison of epifaunal assemblages between Cymodocea nodosa and Caulerpa prolifera meadows in Gran Canaria (eastern Atlantic). Journal of the Marine Biological Association of the United Kingdom 94(2), 241-253. doi:10. 1017/S0025315413001513

Riera, R., Tuya, F., Rodríguez, M., Monterroso, Ó., and Ramos, E. (2013). Confounding response of macrofauna from a confluence of impacts: brine and sewage pollution. Acta Oceanologica Sinica 32(10), 74-81. doi:10.1007/S13131-013-0368-3

Riosmena-Rodríguez, R., and Medina-López, M. A. (2010). The role of rhodolith beds in the recruitment of invertebrate species from the southwestern Gulf of California, Mexico. In 'Seaweeds and their Role in Globally Changing Environments'. pp. 127-138. (Springer: Dordrecht, Netherlands.)

Riosmena-Rodríguez, R., Nelson, W., and Aguirre, J. (Eds) (2017). 'Rhodolith/maërl Beds: a Global Perspective.' (Springer International Publishing: Basel, Switzerland.)

Ruffo, S. (1982). 'The Amphipoda of the Mediterranean. Part 1: Gammaridea (Acanthonotozomatidae to Gammaridae).' Mémoires de l'Institut Océanographique, Monaco 13, p. 364. Prince de Monaco (Monaco).

Sainte-Marie, B. (1991). A review of the reproductive bionomics of aquatic gammaridean amphipods: variation of life history traits with latitude, depth, salinity and superfamily. Hydrobiologia 223, 189-227.
Sanchez-Jerez, P. (1997). Distribución espacio-temporal de la epifauna vágil asociada a praderas de Posidonia oceanica y Cymodocea nodosa (Sudeste Ibérico). Doctoral Dissertation, Universitat d'Alacant Universidad de Alicante, Spain.

Sánchez-Moyano, J., García-Asencio, I., and Carlos García-Gómez, J. (2007). Effects of temporal variation of the seaweed Caulerpa prolifera cover on the associated crustacean community. Marine Ecology 28(2), 324-337. doi:10.1111/J.1439-0485.2006.00141.X

Sciberras, M., Rizzo, M., Mifsud, J. R., Camilleri, K., Borg, J. A., Lanfranco, E., and Schembri, P. J. (2009). Habitat structure and biological characteristics of a maerl bed off the northeastern coast of the Maltese Islands (central Mediterranean). Marine Biodiversity 39(4), 251-264. doi:10. 1007/S12526-009-0017-4

Steller, D. L., and Foster, M. S. (1995). Environmental factors influencing distribution and morphology of rhodoliths in Bahía Concepción, BCS, México. Journal of Experimental Marine Biology and Ecology 194(2), 201-212. doi:10.1016/0022-0981(95)00086-0

Steller, D. L., Hernández-Ayón, J. M., Riosmena-Rodríguez, R., and Cabello-Pasini, A. (2007). Effect of temperature on photosynthesis, growth and calcification rates of the free-living coralline alga Lithophyllum margaritae. Ciencias Marinas 33(4), 441-456. doi:10.7773/ CM.V33I4.1255

Steneck, R. S. (1986). The ecology of coralline algal crusts: convergent patterns and adaptative strategies. Annual Review of Ecology and Systematics 17(1), 273-303. doi:10.1146/ANNUREV.ES.17.110186.001421

Taylor, R. B., and Cole, R. G. (1994). Mobile epifauna on subtidal brown sea-weeds in northeastern New Zealand. Marine Ecology Progress Series 115, 271-282. doi:10.3354/MEPS115271

Teichert, S. (2015). Hollow rhodoliths increase Svalbard's shelf biodiversity. Scientific Reports 4, 6972. doi:10.1038/SREP06972

Thiel, M. (1998). Reproductive biology of a deposit-feeding amphipod, Casco bigelowi, with extended parental care. Marine Biology 132(1), 107-116. doi:10.1007/S002270050376

Thomsen, M. S. (2010). Experimental evidence for positive effects of invasive seaweed on native invertebrates via habitat-formation in a seagrass bed. Aquatic Invasions 5(4), 341-346. doi:10.3391/AI.2010.5.4.02

Thomsen, M. S., Wernberg, T., Altieri, A., Tuya, F., Gulbransen, D., McGlathery, K. J., Holmer, M., and Silliman, B. R. (2010). Habitat cascades: the conceptual context and global relevance of facilitation cascades via habitat formation and modification. Integrative and Comparative Biology 50(2), 158-175. doi:10.1093/ICB/ICQ042

Tuya, F., Cisneros-Aguirre, J., Ortega-Borges, L., and Haroun, R. J. (2007). Bathymetric segregation of sea urchins on reefs of the Canarian Archipelago: role of flow-induced forces. Estuarine, Coastal and Shelf Science 73(3-4), 481-488. doi:10.1016/J.ECSS.2007.02.007

Vázquez-Luis, M., Sanchez-Jerez, P., and Bayle-Sempere, J. T. (2009). Comparison between amphipod assemblages associated with Caulerpa racemosa var. cylindracea and those of other Mediterranean habitats on soft substrate. Estuarine, Coastal and Shelf Science 84(2), 161-170. doi:10.1016/J.ECSS.2009.04.016

Wang, Y., Neuman, U., Wright, S., and Warton, D. I. (2012). mvabund: an R package for model-based analysis of multivariate abundance data. Methods in Ecology and Evolution 3, 471-474. doi:10.1111/J.2041210X.2012.00190.X

Zakhama-Sraieb, R., Sghaier, Y. R., and Charfi-Cheikhrouha, F. (2011). Community structure of amphipods on shallow Posidonia oceanica meadows off Tunisian coasts. Helgoland Marine Research 65(2), 203209. doi:10.1007/S10152-010-0216-1

Zimmerman, R., Gibson, R., and Harrington, J. (1979). Herbivory and detritivory among gammaridean amphipods from a Florida seagrass community. Marine Biology 54(1), 41-47. doi:10.1007/BF00387050

Handling Editor: Thomas Wernberg 